\title{
PORTADORES DE DEFICIÊNCIA a questão da inclusão social
}

\author{
Maria Regina Cazzaniga Maciel \\ Presidente da Associação do 3o Milênio - Centro de Democratização das Ciências da Informação
}

\begin{abstract}
Resumo: A questão da inclusão de pessoas portadoras de necessidades especiais em todos os recursos da sociedade ainda é muito incipiente no Brasil. Movimentos nacionais e internacionais têm buscado um consenso para formatar uma política de inclusão de pessoas portadoras de deficiência na escola regular.

Passos fundamentais devem ser dados para mudar o quadro de marginalização dessas pessoas, como: alteração da visão social; inclusão escolar; acatamento à legislação vigente; maiores verbas para programas sociais; uso da mídia, da cibercultura e de novas tecnologias.

Cabe a todos os integrantes da sociedade lutar para que a inclusão social dessas pessoas seja uma realidade brasileira no próximo milênio.

Palavras-chave: deficiência e exclusão social; educação e economia; política educacional.
\end{abstract}

$\mathrm{H}$ oje, no Brasil, milhares de pessoas com algum tipo de deficiência estão sendo discriminadas nas comunidades em que vivem ou sendo excluídas do mercado de trabalho. O processo de exclusão social de pessoas com deficiência ou alguma necessidade especial é tão antigo quanto a socialização do homem.

A estrutura das sociedades, desde os seus primórdios, sempre inabilitou os portadores de deficiência, marginalizando-os e privando-os de liberdade. Essas pessoas, sem respeito, sem atendimento, sem direitos, sempre foram alvo de atitudes preconceituosas e ações impiedosas.

A literatura clássica e a história do homem refletem esse pensar discriminatório, pois é mais fácil prestar atenção aos impedimentos e às aparências do que aos potenciais e capacidades de tais pessoas.

Nos últimos anos, ações isoladas de educadores e de pais têm promovido e implementado a inclusão, nas escolas, de pessoas com algum tipo de deficiência ou necessidade especial, visando resgatar o respeito humano e a dignidade, no sentido de possibilitar o pleno desenvolvimento e o acesso a todos os recursos da sociedade por parte desse segmento.

Movimentos nacionais e internacionais têm buscado o consenso para a formatação de uma política de integração e de educação inclusiva, sendo que o seu ápice foi a Conferência Mundial de Educação Especial, que contou com a participação de 88 países e 25 organizações inter- nacionais, em assembléia geral, na cidade de Salamanca, na Espanha, em junho de 1994.

Este evento teve como culminância a "Declaração de Salamanca", da qual transcrevem-se, a seguir, pontos importantes, que devem servir de reflexão e mudanças da realidade atual, tão discriminatória.

"Acreditamos e Proclamamos que:

- toda criança tem direito fundamental à educação e deve ser dada a oportunidade de atingir e manter o nível adequado de aprendizagem;

- toda criança possui características, interesses, habilidades e necessidades de aprendizagem que são únicas;

- sistemas educacionais deveriam ser designados e programas educacionais deveriam ser implementados no sentido de se levar em conta a vasta diversidade de tais características e necessidades; - aqueles com necessidades educacionais especiais devem ter acesso à escola regular, que deveria acomodá-los dentro de uma Pedagogia centrada na criança, capaz de satisfazer tais necessidades;

- escolas regulares, que possuam tal orientação inclusiva, constituem os meios mais eficazes de combater atitudes discriminatórias, criando-se comunidades acolhedoras, construindo uma sociedade inclusiva e alcançando educação para todos; além 
disso, tais escolas provêem uma educação efetiva à maioria das crianças e aprimoram a eficiência e, em última instância, o custo da eficácia de todo o sistema educacional.

Nós congregamos todos os governos e demandamos que eles:

- atribuam a mais alta prioridade política e financeira ao aprimoramento de seus sistemas educacionais no sentido de se tornarem aptos a incluírem todas as crianças, independentemente de suas diferenças ou dificuldades individuais;

- adotem o princípio de educação inclusiva em forma de lei ou de política, matriculando todas as crianças em escolas regulares, a menos que existam fortes razões para agir de outra forma;

- desenvolvam projetos de demonstração e encorajem intercâmbios em países que possuam experiências de escolarização inclusiva;

- estabeleçam mecanismos participatórios e descentralizados para planejamento, revisão e avaliação de provisão educacional para crianças e adultos com necessidades educacionais especiais;

- encorajem e facilitem a participação de pais, comunidades e organizações de pessoas portadoras de deficiências nos processos de planejamento e tomada de decisão concernentes à provisão de serviços para necessidades educacionais especiais;

- invistam maiores esforços em estratégias de identificação e intervenção precoces, bem como nos aspectos vocacionais da educação inclusiva;

- garantam que, no contexto de uma mudança sistêmica, programas de treinamento de professores, tanto em serviço como durante a formação, incluam a provisão de educação especial dentro das escolas inclusivas.

Nós também congregamos a comunidade internacional; em particular, nós congregamos governos com programas de cooperação internacional, agências financiadoras internacionais, especialmente as responsáveis pela Conferência Mundial em Educação para Todos, Unesco, Unicef, UNDP e o Banco Mundial:

- a endossar a perspectiva de escolarização inclusiva e apoiar o desenvolvimento da educação especial como parte integrante de todos os programas educacionais;
- as Nações Unidas e suas agências especializadas, em particular a ILO, WHO, Unesco e Unicef;

- a reforçar seus estímulos de cooperação técnica, bem como reforçar suas cooperações e redes de trabalho para um apoio mais eficaz à já expandida e integrada provisão em educação especial;

- a reforçar sua colaboração com as entidades oficiais nacionais e intensificar o envolvimento crescente delas no planejamento, implementação e avaliação de provisão em educação especial que seja inclusiva;

- Unesco, enquanto a agência educacional das Nações Unidas;

- a assegurar que educação especial faça parte de toda discussão que lide com educação para todos em vários foros;

- a mobilizar o apoio de organizações dos profissionais de ensino em questões relativas ao aprimoramento do treinamento de professores no que diz respeito a necessidades educacionais especiais;

- a estimular a comunidade acadêmica no sentido de fortalecer pesquisa, redes de trabalho e o estabelecimento de centros regionais de informação e documentação e, da mesma forma, a servir de exemplo em tais atividades e na disseminação dos resultados específicos e dos progressos alcançados em cada país no sentido de realizar o que almeja a presente Declaração;

- a mobilizar Fundos através da criação (dentro de seu próximo Planejamento a Médio Prazo 1996-2000) de um programa extensivo de escolas inclusivas e programas de apoio comunitário, que permitiriam o lançamento de projetos-piloto que demonstrassem novas formas de disseminação e o desenvolvimento de indicadores de necessidade e de provisão de educação especial".

A inclusão escolar, fortalecida pela Declaração de Salamanca, no entanto, não resolve todos os problemas de marginalização dessas pessoas, pois o processo de exclusão é anterior ao período de escolarização, iniciandose no nascimento ou exatamente no momento em aparece algum tipo de deficiência física ou mental, adquirida ou hereditária, em algum membro da família. Isso ocorre em qualquer tipo de constituição familiar, sejam as tradicionalmente estruturadas, sejam as produções independentes e congêneres e em todas as classes sociais, com um agravante para as menos favorecidas. 
O nascimento de um bebê com deficiência ou o aparecimento de qualquer necessidade especial em algum membro da família altera consideravelmente a rotina no lar. Os pais logo se perguntam: por quê? De quem é a culpa? Como agirei daqui para frente? Como será o futuro de meu filho?

O imaginário, então, toma conta das atitudes desses pais ou responsáveis e a dinâmica familiar fica fragilizada. Imediatamente instalam-se a insegurança, o complexo de culpa, o medo do futuro, a rejeição e a revolta, uma vez que esses pais percebem que, a partir da deficiência instalada, terão um longo e tortuoso caminho de combate à discriminação e ao isolamento.

O quadro fica mais sério, tendo em vista que a tendência dos profissionais da saúde é sempre ressaltar, no diagnóstico, os aspectos limitantes da deficiência, pois invariavelmente são eles que primeiro são chamados para dar o diagnóstico conclusivo. Os médicos raramente esclarecem ou informam, aos familiares de portadores de deficiência, as possibilidades de desenvolvimento, as formas de superação das dificuldades, os locais de orientação familiar, os recursos de estimulação precoce, os centros de educação e de terapia.

A esses familiares pede-se que aceitem uma realidade que não desejam e que não é prevista, uma realidade em que os meios sociais e a mídia pouco abordam e, quando o fazem, é de maneira superficial, às vezes preconceituosa e sem apresentar os caminhos para a inclusão social.

Os pais ou responsáveis por portadores de deficiência, por sua vez, também se tornam pessoas com necessidades especiais: eles precisam de orientação e principalmente do acesso a grupos de apoio. Na verdade, são eles que intermediarão a integração ou inclusão de seus filhos junto à comunidade.

Cada deficiência acaba acarretando um tipo de comportamento e suscitando diferentes formas de reações, preconceitos e inquietações. As deficiências físicas, tais como paralisias, ausência de visão ou de membros, causam imediatamente apreensão mais intensa por terem maior visibilidade. Já a deficiência mental e a auditiva, por sua vez, são pouco percebidas inicialmente pelas pessoas, mas causam mais estresse, à medida que se toma consciência da realidade das mesmas.

A falta de conhecimento da sociedade, em geral, faz com que a deficiência seja considerada uma doença crônica, um peso ou um problema. O estigma da deficiência é grave, transformando as pessoas cegas, surdas e com deficiências mentais ou físicas em seres incapazes, inde- fesos, sem direitos, sempre deixados para o segundo lugar na ordem das coisas. É necessário muito esforço para superar este estigma.

Essa situação se intensifica junto aos mais carentes, pois a falta de recursos econômicos diminui as chances de um atendimento de qualidade. Tem-se aí um agravante: o potencial e as habilidades dessas pessoas são pouco valorizados nas suas comunidades de origem, que, obviamente, possuem pouco esclarecimento a respeito das deficiências. Onde estão as causas da exclusão dessas pessoas no Brasil?

No plano de governo, o que se vê são programas, propostas, projetos, leis e decretos com lindas e sonoras siglas, que ficam, na maioria das vezes, só no papel. Programas similares e simultâneos são lançados em duas ou três pastas, sem que haja integração de objetivos e metas entre eles.

Muitas vezes acontecem ações paralelas entre o governo e a iniciativa privada, que ficam desintegradas, superpostas, sem consistência e dirigidas a pequenos grupos, gastando verbas sem mudar o quadro de exclusão existente.

Essas ações não são permanentes, pois a cada mudança de governo são interrompidas, esvaziadas, perdendo a continuidade e a abrangência, sendo que outras aparecem em seus lugares para "fixar" a plataforma de quem está no poder.

Nos estados e municípios, não existe uma política efetiva de inclusão que viabilize planos integrados de urbanização, de acessibilidade, de saúde, educação, esporte, cultura, com metas e ações convergindo para a obtenção de um mesmo objetivo: resguardar o direito dos portadores de deficiência.

As dificuldades são imensas para sensibilizar executivos de empresas privadas, técnicos de órgãos públicos e educadores sobre essa questão. Um sentimento de omissão aparece, consciente ou inconscientemente, em técnicos, executivos e burocratas, quando necessitam decidir sobre o atendimento às necessidades dos portadores de deficiência.

Essas reações preconceituosas, de omissão e descaso, já podem ser classificadas:

- nos órgãos públicos, as solicitações e reivindicações de pessoas portadoras de deficiência logo se transformam nos famosos processos "Ao-Ao", em que cotas endereçadas "Ao" Dr. Fulano, "Ao" departamento tal e "Ao" setor de Sicrano só criam volume, burocracia e não apontam para soluções, pois todos transferem o "problema" para terceiros, eximindo-se, assim, da necessidade de propor al- 
ternativas de atendimento. Nesses processos, quase todos se omitem de tomar decisões em benefício dos portadores de deficiência;

- na área de atendimento e serviços à população, a resposta mais freqüente é a "NTV" - "não temos vaga";

- há, também, a adoção, tão popular para as pessoas de baixa renda, do sistema "ENFE" de atendimento, ou seja, "entre na fila de espera".

Por outro lado, a idéia de modelos únicos para todos, preestabelecidos, tem excluído pessoas com necessidades especiais dos recursos da sociedade, como comprovam as barreiras arquitetônicas, sociais e educacionais. No plano dos atendimentos específicos, a realidade é a seguinte:

- saúde: os locais de atendimentos na área de saúde são pequenos, superlotados e sem infra-estrutura. As políticas de prevenção, às vezes, ficam restritas a algumas campanhas de vacinação e os programas de diagnóstico precoce são insuficientes. Os testes com aparelhos de última geração são destinados a poucos; as de terapias e fisioterapias oferecem poucas vagas em relação à demanda; a obtenção de próteses e órteses é difícil e as filas de espera são enormes para quem não tem poder aquisitivo;

- área social: os programas para as pessoas com alguma deficiência são, em geral, os que possuem as menores verbas, não existe trabalho efetivo junto às comunidades mais carentes e os grupos de orientação e atendimento estão sempre superlotados;

- mercado de trabalho: poucos são os empregadores que se dispõem a absorver esse segmento. O portador de deficiência é o último a ser contratado e o primeiro a ser demitido, sendo que sua faixa salarial é, em média, menor que a de seus colegas de profissão;

- nas áreas de lazer, esportes, cultura e transportes não existem projetos abrangentes que atendam a todos os tipos de deficiência e, nas áreas de comércio, indústria e serviços, a acessibilidade inexiste ou é inconsistente;

- na educação também não é diferente, pois só as grandes cidades possuem algum tipo de atendimento. A realidade tem mostrado que os ciclos do ensino fundamental, com sua passagem automática de ano, e a falta de formação de professores, de recursos técnico-pedagógicos, de estímulo suplementar, de acompanhamento de equipe multidisciplinar - fonoaudiólogos, assistentes sociais, psicólogos, terapeutas ocupacionais -, de salas e de professores de apoio deixam a questão da inclusão escolar sem estrutura eficiente, bonita apenas na teoria.
Em nome da igualdade de atendimentos, muitos teóricos radicais defendem a inclusão escolar de forma simplista: é só colocar esse aluno na classe comum e tudo se resolve. Entretanto, suas teses não refletem a realidade de que as pessoas com deficiência possuem necessidades educativas especiais e, assim, pouca contribuição têm trazido para todos os envolvidos na questão. Também em nome da igualdade de atendimentos, muitos deles negam veementemente as experiências positivas de escolas e de classes especiais, que souberam desenvolver o potencial de seus alunos e, dessa forma, contribuíram para a sua inclusão junto à sociedade. Negar os trabalhos positivos do passado é esquecer que a construção do conhecimento está baseada no acúmulo de experiência adquirida.

Deve-se lembrar, sempre, que o princípio fundamental da sociedade inclusiva é o de que todas as pessoas portadoras de deficiência devem ter suas necessidades especiais atendidas. É no atendimento das diversidades que se encontra a democracia. O que fazer diante deste quadro? O primeiro passo é conseguir a alteração da visão social através:

- de um trabalho de sensibilização contínuo e permanente por parte de grupos e instituições que já atingiram um grau efetivo de compromisso com a inclusão de portadores de necessidades especiais junto à sociedade;

- da capacitação de profissionais de todas as áreas para o atendimento das pessoas com algum tipo de deficiência; - da elaboração de projetos que ampliem e inovem o atendimento dessa clientela;

- da divulgação da Declaração de Salamanca e outros documentos congêneres, da legislação, de informações e necessidades dos portadores de deficiência e da importância de sua participação em todos os setores da sociedade.

A reestruturação das instituições não deve ser apenas uma tarefa técnica, pois depende, acima de tudo, de mudanças de atitudes, de compromisso e disposição dos indivíduos. O segundo passo no processo de inclusão social é o da inclusão escolar.

Ao entrarem para a escola, as crianças que possuem alguma necessidade educativa especial terão que se integrar e participar obrigatoriamente de três estruturas distintas da dinâmica escolar: o ambiente de aprendizagem; a integração professor-aluno; e a interação aluno-aluno.

A partir da análise e adequação destas estruturas e do levantamento de alternativas que favoreçam o desenvolvimento dos alunos, em geral, e dos portadores de neces- 
sidades educativas especiais, em particular, é que a inclusão escolar deve ter início. Assim, é necessário analisar se o ambiente de aprendizagem é favorecedor, se existe oferta de recursos audiovisuais, se ocorreu a eliminação de barreiras arquitetônicas, sonoras e visuais de todo o próprio escolar, se existem salas de apoio pedagógico para estimulação e acompanhamento suplementar, se os currículos e estratégias de ensino estão adequados à realidade dos alunos e se todos os que compõem a comunidade escolar estão sensibilizados para atender o portador de deficiência com respeito e consideração.

Para que haja a verdadeira integração professor-aluno, é necessário que o professor da sala regular e os especialistas de educação das escolas tenham conhecimento sobre o que é deficiência, quais são seus principais tipos, causas, características e as necessidades educativas de cada deficiência. O professor precisa, antes de tudo, ter ampla visão desta área, que deve ser proveniente de sua formação acadêmica. Hoje, poucas escolas e universidades, que formam professores, abordam adequadamente a questão da deficiência em seus currículos. Urge mudar essa realidade. A atualização periódica também é indispensável, devendo ocorrer por meio de cursos, seminários e formação em serviço.

É importante que os professores tomem ciência do diagnóstico e do prognóstico do aluno com necessidades educativas especiais, entrevistem pais ou responsáveis para conhecer todo o histórico de vida desse aluno, a fim de traçar estratégias conjuntas de estimulação família-escola, peçam orientações e procurem profissionais - como psicólogos, fisioterapeutas, fonoaudiólogos - que estejam atendendo ou que já atenderam esses alunos, solicitando relatórios e avaliações, e pesquisem várias técnicas, métodos e estratégias de ensino, em que variáveis como o desenvolvimento da linguagem, o desenvolvimento físico e sobretudo as experiências sociais estejam presentes.

A integração professor-aluno só ocorre quando há uma visão despida de preconceito, cabendo ao professor favorecer o contínuo desenvolvimento dos alunos com necessidades educativas especiais. Não é tarefa fácil, mas é possível. Quando ocorre, torna-se uma experiência inesquecível para ambos.

A interação aluno-aluno traz à tona as diferenças interpessoais, as realidades e experiências distintas que os mesmos trazem do ambiente familiar, a forma como eles lidam com o diferente, os preconceitos e a falta de paciência em aceitar o outro como ele é. Todos os alunos das classes regulares devem receber orientações sobre a questão da deficiência e as formas de convivência que respeitem as diferenças, o que não é tarefa fácil, mas possível de ser realizada. Levar os alunos de classes regulares a aceitarem e respeitarem os portadores de deficiência é um ato de cidadania.

Cabe a todos profissionais de escolas especiais, de classes especiais, de salas de apoio a portadores de necessidades especiais, aos teóricos da educação inclusiva, aos profissionais das escolas regulares e às equipes multidisciplinares e de saúde a função primordial da integração de ações, da otimização dos recursos e dos atendimentos, da criação de canais de comunicação que considerem a questão da inclusão social como prioritária e anterior à inclusão escolar.

O futuro é outra dimensão que também não pode ser esquecida, pois é preciso estar preparado para a rápida evolução tecnológica destes novos tempos, que influencia e modifica o processo educativo e a nossa relação com a construção do conhecimento.

Para a estimulação da pessoa com deficiência, a tecnologia da informação é fundamental, pois a velocidade da renovação do saber e as formas interativas da cibercultura trazem uma nova expectativa de educação para essa clientela. É necessário, portanto, criar serviços e propostas educativas abertas e flexíveis que atendam às necessidades de mudanças.

A cibercultura não só demonstra que a maior parte dos conhecimentos adquiridos por uma pessoa no início de sua vida educacional estará ultrapassada ao final de um certo tempo, como também aponta novas formas de habilitação e reabilitação de pessoas com necessidades educativas especiais. Esse fenômeno de captação de transformações constantes deve ser posto ao alcance das pessoas com necessidades especiais.

O terceiro passo para a inclusão social de portadores de deficiência é a instituição de mecanismos fortalecedores desses direitos, tais como destinação de maiores verbas públicas para os projetos que atendam esse segmento e participação de entidades de defesa de deficientes e para deficientes nos processos decisórios de todas as áreas diretamente envolvidas no atendimento dessa população.

A mídia não pode ser esquecida, pois possui um papel fundamental na promoção de atitudes positivas no sentido da inclusão de pessoas portadoras de deficiência na sociedade. A criação de equipes de mediação de sistemas e a presença de ombudsmen junto aos conselhos de defesa da pessoa deficiente, que mostrem ao governo, à sociedade e à mídia os acertos e desacertos da inclusão so- 
cial e escolar e seus prognósticos para curto, médio e longo prazos, devem ser consideradas.

A prática da desmarginalização de portadores de deficiência deve ser parte integrante de planos nacionais de educação, que objetivem atingir educação para todos. A inclusão social traz no seu bojo a equiparação de oportunidades, a mútua interação de pessoas com e sem deficiência e o pleno acesso aos recursos da sociedade. Cabe lembrar que uma sociedade inclusiva tem o compromisso com as minorias e não apenas com as pessoas portadoras de deficiência. A inclusão social é, na verdade, uma medida de ordem econômica, uma vez que o portador de deficiência e outras minorias tornam-se cidadãos produtivos, participantes, conscientes de seus direitos e deveres, diminuindo, assim, os custos sociais. Dessa forma, lutar a favor da inclusão social deve ser responsabilidade de cada um e de todos coletivamente.

\section{REFERÊNCIAS BIBLIOGRÁFICAS}

BURKE, C. A special kind of hero. Nova York, Barron's, 1993.

BUSCAGLIA, L. Os deficientes e seus pais. Rio de Janeiro, Record, 1993. PERKE, R. New life in the Neighborhood. United States, Paternon, 1980.

UNICEF, OMS, UNESCO. Medidas vitais. Brasília, Seguradoras, s/d. 